\title{
Characteristics of unintentional drowning deaths in children with autism spectrum disorder
}

\author{
Joseph Guan ${ }^{1}$ and Guohua Li ${ }^{1,2,3^{*}}$
}

\begin{abstract}
Background: The reported prevalence of autism spectrum disorder (ASD) has increased markedly in the past two decades. Recent research indicates that children with ASD are at a substantially increased risk of injury mortality, particularly from unintentional drowning. The purpose of this study was to explore the circumstances of fatal unintentional drowning incidents involving children with ASD under 15 years of age.

Findings: During January 2000 through May 2017, US newspapers reported a total of 23 fatal drowning incidents involving 18 boys and 5 girls with ASD. Age of victims ranged from 3 to 14 years (mean $=7.7 \pm 2.9$ years). These drowning incidents most commonly occurred in ponds (52.2\%), followed by rivers (13.0\%), and lakes (13.0\%). For 11 incidents with location data available, the distance between victim residence and the water body where drowning occurred averaged $290.7 \mathrm{~m}$ ( $\pm 231.5 \mathrm{~m}$ ). About three-quarters (73.3\%) of the drowning incidents occurred in the afternoon hours from 12:00 to 18:59. Wandering was the most commonly reported activity that led to drowning, accounting for $73.9 \%$ of the incidents.
\end{abstract}

Conclusions: Fatal drowning in children with ASD typically occur in water bodies near the victims' homes in the afternoon hours precipitated by wandering. Multifaceted intervention programs are urgently needed to reduce the excess risk of drowning in children with ASD.

Keywords: Accidental death, Autism, Drowning, Epidemiology, Injury, Wandering

\section{Background}

Autism spectrum disorder (ASD) is a complex neurodevelopmental disability characterized by repetitive behaviors and impairments in social and communication skills (American Psychiatric Association, 2013). Symptoms may emerge in early childhood, usually beginning at age 2 to 3 years, and last throughout adulthood (American Psychiatric Association, 2013; National Institute of Mental Health, 2016; Perou et al., 2013). Some people with ASD demonstrate maladaptive behaviors including self-harm, wandering, aggression, and uncontrolled outbursts from anger or irritation (Carroll et al., 2014; Green et al., 2000; Kanne \& Mazurek, 2011). Autism can co-occur with other

\footnotetext{
* Correspondence: GL2240@cumc.columbia.edu

1 Department of Epidemiology, Columbia University Mailman School of Public Health, DrPH; 622 West 168th St, New York, NY PH5-505, USA

${ }^{2}$ Department of Anesthesiology, Columbia University College of Physicians and Surgeons, New York, NY, USA

Full list of author information is available at the end of the article
}

medical and developmental conditions (e.g. epilepsy and intellectual disability) and symptoms that pose potential challenges to everyday functioning (American Psychiatric Association, 2013).

The reported prevalence of ASD has increased considerably over the past two decades, from 1 in 150 children to about 1 in 68 children (Centers for Disease Control and Prevention, 2017; Christensen et al., 2016). Currently, there is an estimated 3.5 million people living with ASD in the United States, including approximately 850,000 children under the age of 17 years (Buescher et al., 2014).

Although little is known about the long-term health outcomes of people with ASD, research indicates that individuals with this disorder are at up to 10-fold increased risk of premature death compared to the general population (Rice et al., 2016; Gillberg et al., 2010; Mouridsen et al., 2008; Pickett et al., 2011). A recent study provided compelling evidence that compared to the 
general pediatric population, children with ASD are at a substantially heightened risk of unintentional injury, in particularly drowning (Guan \& Li, 2017). Although drowning remains a major cause of childhood mortality worldwide, the circumstances preceding the incidents are often understudied or undocumented in death records (World Health Organization Global Report on Drowning, 2014). In order to develop targeted strategies to reduce the excess risk of drowning, it is imperative to understand the circumstances of the drowning incidents. Thus, the purpose of this study was to examine the frequency and characteristics of fatal unintentional drowning incidents involving children with ASD.

\section{Methods}

The Lexis-Nexis Academic database is a web-based research database that contains archives of full-text documents from over 17,000 sources including newspapers, journals, wire services, business and company publications, and legal government documents. The database was queried using terms (('autism' OR 'autistic') AND ('drowning' or 'drowned') AND ('boy' or 'girl')) that appeared in the headline or body of the newspaper articles to identify the drowning incidents involving children under age 15 years with ASD in the United States from January 2000 through May 2017. Duplicate options were set for 'On-high similarity'.

All items returned from the query were screened and information related to the victims and details of the incidents, including time of day and distance from residence, were ascertained from the newspaper reports and analyzed using descriptive statistics.

\section{Results}

During January 2000 through May 2017, US newspapers reported a total of 23 fatal unintentional drowning incidents involving children under 15 years of age with ASD. Of the 23 incidents, 14 (60.9\%) occurred between 2010 and 2016. There was no incident reported in 2017 as of May 31st, 2017. The majority (78.3\%) of the victims were boys. Age of drowning victims ranged from 3 to 14 years (mean $=7.7 \pm 2.9$ years), with female victims being 1.1 years younger on average than male victims (Fig. 1). The most common water body where the fatal drowning incidents occurred was ponds (52.2\%), followed by lakes (13.0\%), and rivers (13.0\%) (Table 1). Data about proximity of the water body to the victim's residence were available for $11(47.8 \%)$ of the incidents, with all of them within $1000 \mathrm{~m}$ of the victim's residence $($ mean $=290.7 \pm 231.5 \mathrm{~m})$. The time of day at which victims were reported missing was available for $15(65.2 \%)$ of 23 incidents, with $2(13.3 \%)$ being in the morning (0:0011:59), 11 (73.3\%) being in the afternoon (12:00-17:59), and 2 (13.3\%) being in the evening (18:00 PM - 23:59)

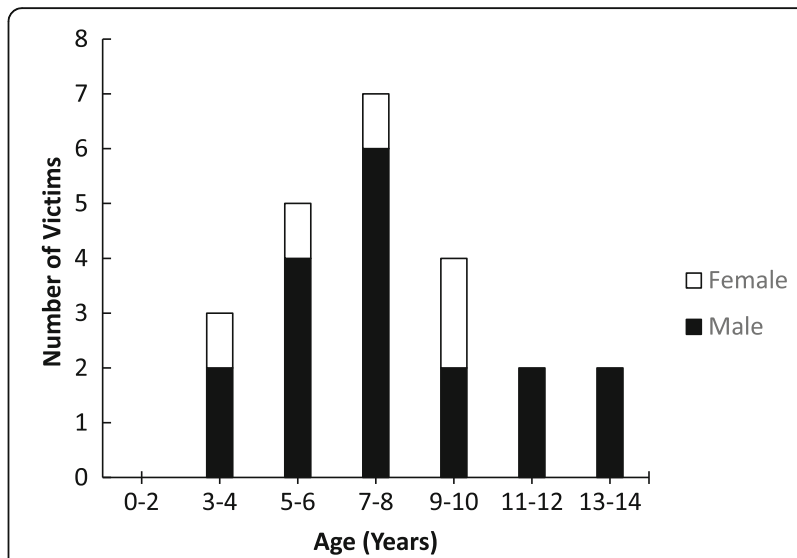

Fig. 1 Age Distribution of Fatal Unintentional Drowning Incidents Involving Children with Autism Spectrum Disorder by Sex as Reported in US Newspapers, January 2000 - May 2017

(Fig. 2). The drowning incidents occurred most frequently in the month of June (21.7\%). Wandering was the most commonly reported activity that led to drowning, accounting for $73.9 \%$ of the incidents (Table 1 ).

\section{Discussion}

The results of this study indicate that fatal unintentional drownings involving children with ASD reported in US newspapers have increased considerably since 2010. One plausible explanation for this increase might be the increased prevalence and awareness of ASD (Guan \& Li, 2017). Furthermore, the results indicate that fatal unintentional drowning in children with ASD typically involved boys aged 7-8 years.

Our results also show that most of the victims wandered away from their residence and drowned in nearby ponds. Previous studies have suggested that wandering

Table 1 Circumstances of Fatal Accidental Drowning Incidents Involving Children with Autism Spectrum Disorder as Reported in US Newspapers, January 2000 - May 2017

\begin{tabular}{ll}
\hline Circumstance & $n(\%)$ \\
\hline Water body type & $12(52.2)$ \\
Pond & $3(13.0)$ \\
Lake & $3(13.0)$ \\
River & $2(8.7)$ \\
Creek & $1(4.3)$ \\
Private pool & $1(4.3)$ \\
Public pool & $1(4.3)$ \\
Bathtub & \\
Activity leading to drowning & $17(73.9)$ \\
Wandering & $1(4.3)$ \\
Left unattended to & $5(21.7)$ \\
Unspecified &
\end{tabular}




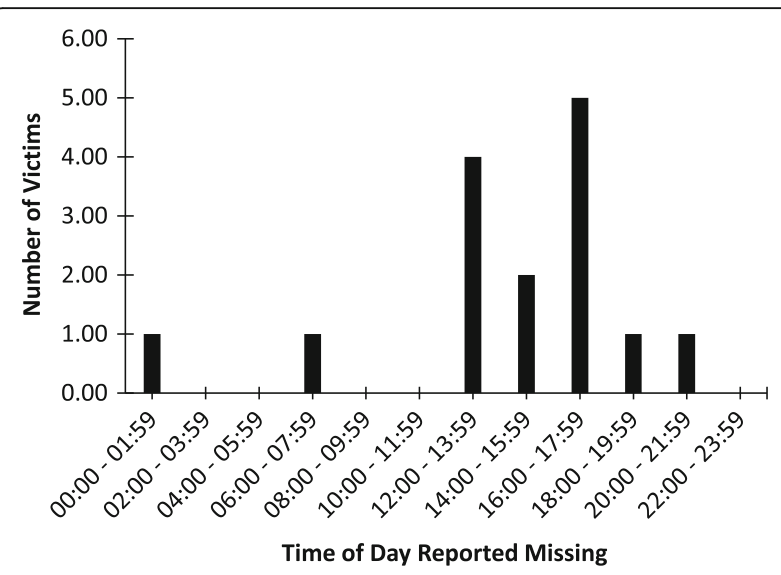

Fig. 2 Time of Day Distribution of Fatal Unintentional Drowning Incidents Involving Children with Autism Spectrum Disorder as Reported in US Newspapers, January 2000 - May 2017

behavior is highest among children with ASD and intellectual disability, especially among boys between 6 and 11 years of age (Rice et al., 2016; Kiely et al., 2016; Barnard-Brak et al., 2016; Anderson et al., 2012). One often cited contributing factor for child drowning is a lapse in or lack of caregiver supervision (Blum \& Shield, 2000; Hyder et al., 2009). Therefore, autistic children showing the tendency of wandering may benefit from real-time monitoring through global positioning system devices. Drowning risk assessment (e.g., proximity of water bodies) and risk reduction in the residential environment (e.g., barriers to water bodies) should also be considered. In residential environments for children with $\mathrm{ASD}$, it is desirable to have devices that quickly alert parents and guardians when the children elope from the premises.

According to the narratives provided in the news reports, many of the drowning victims were fascinated with water and drowned in "unfenced" or "unguarded" ponds. While it is necessary to mitigate the behavioral and environmental risks by restricting access into water bodies through secured barriers or fences (Leavy et al., 2016; Wallis et al., 2015), parents, pediatricians, and other caretakers should help provide swimming lessons to these children as soon as the diagnosis is made (Guan $\& \mathrm{Li}, 2017)$. Studies have shown that children who receive swimming and water safety (e.g., survival flotation, energy conservation, and safety behavior) lessons at an earlier age will acquire the skills faster and thus may improve their survival chances in dangerous situations (Wallis et al., 2015). It is feasible and effective to improve water safety skills in children with ASD through aquatic training (Alaniz et al., 2017). In addition, parents should be encouraged to receive water safety training, which may help reduce the drowning risk for their children (Leavy et al., 2016).
This study is limited by the small sample size and the availability of information reported in newspaper articles. Often, basic demographic data and other important details are missed in newspaper reports (Baullinger et al., 2001; Voight et al., 1998). As a resource for sentinel injury surveillance, newspaper reports are likely to uncover only the tip of the "iceberg." In order to have a more complete understanding and develop interventions to reduce the excess risk of unintentional drowning involving children with ASD, future studies should use more rigorously collected data from injury surveillance systems.

\section{Conclusions}

Findings from this study indicate that fatal unintentional drownings involving children with ASD reported in US newspapers have increased in the recent years. These incidents occur commonly in unsecured ponds, rivers, and lakes that are in near proximity to the victims' residence. Furthermore, fatal unintentional drownings in children with ASD typically involve boys ages $7-8$ years who wander away from home to nearby ponds in the afternoon hours. Given these findings, intervention programs for children with ASD should be developed to prevent these children from getting into bodies of water unsupervised. Furthermore, to reduce the excess risk of drowning, children with ASD should be provided with swimming lessons and water safety training immediately following diagnosis.

\section{Acknowledgements}

The authors thank Barbara H. Lang, MPH, for administrative and editorial assistance.

\section{Funding}

This research was supported by Grants R49 CE002096 from the National Center for Injury Prevention and Control, Centers for Disease Control and Prevention. The contents of the manuscript are solely the responsibility of the authors and do not necessarily reflect the official views of the funding agency.

\section{Authors' contributions}

JG collected and analyzed the data, reviewed the literature, and drafted the manuscript. GL conceived the study, secured funding, supervised the literature search and statistical analysis, and contributed to critical revisions of the manuscript. Both authors read and approved the final manuscript.

\section{Ethics approval and consent to participate}

This study is based on data from newspaper reports on fatal drowning incidents and is considered non-human subjects research by Columbia University's institutional review board.

\section{Competing interests}

Dr. Guohua Li serves as editor-in-chief of the journal, Injury Epidemiology, and was not involved in the review or handling of this manuscript.

The authors have no other competing interests to disclose.

\section{Publisher's Note}

Springer Nature remains neutral with regard to jurisdictional claims in published maps and institutional affiliations. 


\section{Author details}

'Department of Epidemiology, Columbia University Mailman School of Public Health, DrPH; 622 West 168th St, New York, NY PH5-505, USA. ²Department of Anesthesiology, Columbia University College of Physicians and Surgeons, New York, NY, USA. ${ }^{3}$ Center for Injury Epidemiology and Prevention, Columbia University Medical Center, New York, NY, USA.

Received: 5 September 2017 Accepted: 15 November 2017

Published online: 08 December 2017

\section{References}

Alaniz ML, Rosenberg SS, Beard NR, Rosario ER. The effectiveness of aquatic group therapy for improving water safety and social interactions in children with autism spectrum disorder: a pilot program. J Autism Dev Disord. 2017:47(12):4006-17.

American Psychiatric Association. Diagnostic and statistical manual of mental disorders: DSM-5. 5th ed. Washington, D.C: American Psychiatric Association; 2013. p. 50-9.

Anderson C, Law JK, Daniels A, Rice C, Mandell DS, Hagopian L, et al. Occurrence and family impact of elopement in children with autism spectrum disorders. Pediatrics. 2012;130(5):870-7.

Barnard-Brak L, Richman DM, Moreno R. Predictors of elopement exhibited by school-aged children with special health care needs: towards the development of a screening instrument for elopement. J Prim Prev. 2016;37(6):543-54.

Baullinger J, Quan L, Bennett E, Cummings P, Williams K. Use of Washington state newspapers for submersion injury surveillance. Inj Prev. 2001;7(4):339-42.

Blum C, Shield J. Toddler drowning in domestic swimming pools. Inj Prev. 2000;6(4):288-90.

Buescher AV, Cidav Z, Knapp M, Mandell DS. Costs of autism spectrum disorders in the United Kingdom and the United States. JAMA Pediatr. 2014;168(8): $721-8$.

Carroll D, Hallett V, McDougle CJ, Aman MG, McCracken JT, Tierney E, et al. Examination of aggression and self-injury in children with autism spectrum disorders and serious behavioral problems. Child Adolesc Psychiatr Clin N Am. 2014;23(1):57-72.

Centers for Disease Control and Prevention. Autism Spectrum Disoder (ASD) 2017 [Available from: https://www.cdc.gov/ncbddd/autism/data.html.

Christensen DL, Baio J, Van Naarden BK, Bilder D, Charles J, Constantino JN, et al. Prevalence and characteristics of autism Spectrum disorder among children aged 8 years-autism and developmental disabilities monitoring network, 11 sites, United States, 2012. MMWR Surveill Summ. 2016;65(3):1-23.

Gillberg C, Billstedt E, Sundh V, Gillberg IC. Mortality in autism: a prospective longitudinal community-based study. J Autism Dev Disord. 2010;40(3):352-7.

Green J, Gilchrist A, Burton D, Cox A. Social and psychiatric functioning in adolescents with Asperger syndrome compared with conduct disorder J Autism Dev Disord. 2000;30(4):279-93.

Guan J, Li G. Injury mortality in individuals with autism. Am J Public Health. 2017;107(5):791-3.

Hyder AA, Sugerman DE, Puvanachandra P, Razzak J, El-Sayed H, Isaza A, et al. Global childhood unintentional injury surveillance in four cities in developing countries: a pilot study. Bull World Health Organ. 2009;87(5):345-52.

Kanne SM, Mazurek MO. Aggression in children and adolescents with ASD: prevalence and risk factors. J Autism Dev Disord. 2011;41(7):926-37.

Kiely B, Migdal TR, Vettam S, Adesman A. Prevalence and correlates of elopement in a nationally representative sample of children with developmental disabilities in the United States. PLoS One. 2016;11(2):e0148337.

Leavy JE, Crawford G, Leaversuch F, Nimmo L, McCausland K, Jancey JA. Review of drowning prevention interventions for children and young people in high, low and middle income countries. J Community Health. 2016;41(2):424-41.

Mouridsen SE, Bronnum-Hansen H, Rich B, Isager T. Mortality and causes of death in autism spectrum disorders: an update. Autism. 2008;12(4):403-14.

National Institute of Mental Health. Autism Spectrum Disorder 2016 [updated October 2016. Available from: https://www.nimh.nih.gov/health/topics/ autism-spectrum-disorders-asd/index.shtml.

Perou R, Bitsko RH, Blumberg SJ, Pastor P, Ghandour RM, Gfroerer JC, et al. Mental health surveillance among children-United States, 2005-2011. MMWR Suppl. 2013;62(2):1-35.

Pickett J, Xiu E, Tuchman R, Dawson G, Lajonchere C. Mortality in individuals with autism, with and without epilepsy. J Child Neurol. 2011;26(8):932-9.
Rice CE, Zablotsky B, Avila RM, Colpe LJ, Schieve LA, Pringle B, et al. Reported wandering behavior among children with autism Spectrum disorder and/or intellectual disability. J Pediatr. 2016;174:232-9. e2

Voight B, Lapidus G, Zavoski R, Banco L. Injury reporting in Connecticut newspapers. Inj Prev. 1998;4(4):292-4.

Wallis BA, Watt K, Franklin RC, Taylor M, Nixon JW, Kimble RM. Interventions associated with drowning prevention in children and adolescents: systematic literature review. Inj Prev. 2015;21(3):195-204.

World Health Organization Global report on drowning. Switzerland, Geneva: world health Organization, 2014. Available from: http://www.who.int/violence_injury_ prevention/global_report_drowning/Final_report_full_web.pdf.

\section{Submit your manuscript to a SpringerOpen ${ }^{\mathcal{D}}$ journal and benefit from:}

- Convenient online submission

- Rigorous peer review

- Open access: articles freely available online

- High visibility within the field

- Retaining the copyright to your article

Submit your next manuscript at $>$ springeropen.com 